who had undergone appendicectomy were aged over 20 years at the time of operation. In the appendicitis group only two of the 17 parents affected were older than 20 .

\section{Discussion}

In so far as appendicectomy is related to acute appendicitis our results suggest that there is a familial predisposition to appendicitis in childhood. This might be attributed to a familial dietary factor, in particular a low-fibre diet, which could predispose to faecolith formation and obstruction of the appendix lumen. ${ }^{6}$ The geographical distribution of appendicitis in developed Western countries has been cited in support of this theory. ${ }^{8}$ In the absence of a controlled study taking account of genetic, nutritional, and geographical considerations the theory is difficult to sustain, since $40^{\circ}$ of normal appendices contain faecoliths ${ }^{9}$ compared with only $10^{\circ}{ }_{0}$ of inflamed appendices. ${ }^{6}$

Another explanation of the familial predisposition is some genetic mechanism, possibly a polygenic inheritance. This would also be supported by the geographical distribution of the condition. Inherited developmental anomalies of the anatomy of the appendix have been suggested as one possible mechanism for any familial predisposition to acute appendicitis. ${ }^{10}$
A family history of appendicectomy might provide a useful contributory indication for appendicectomy, although a negative family history would not, of course, preclude acute appendicitis.

We should like to thank Dr E R Verrier Jones, Dr E N Thompson, Dr J Sibert, Mr M Wheeler, Mr A Aubrey, and Mr H Vernon Jones, whose patients were used in this study. Thanks also go to Llandough Hospital records department for help and co-operation and to $\mathrm{Dr} R$ Seal of the pathology department for permission to use pathology records.

\section{References}

1 Van Meter, S D, Colorado Medicine, 1920, 17, 241.

2 Baker, E G S, Fournal of Heredity, 1937, 28, 187.

${ }^{3}$ Perry, T, and Keeler, C E, American fournal of Surgery, 1939, 46, 259.

${ }^{4}$ Nusselt, S, Medizin Monatsschrift, 1977, 31, 232.

5 Budd, D C, and Foulty, W J, American Fournal of Surgery, 1977, 133, 670.

${ }^{6}$ Johnson, J R, British Medical fournal, 1978, 1, 305.

' Horton, L W C, British Medical fournal, 1978, 2, 1672.

${ }^{8}$ Burkitt, D P, British fournal of Surgery, 1971, 58, 695.

${ }^{9}$ Burkitt, D P, Moolgaokar, A S, and Tovey, F I, British Medical fournal, $1979,1,620$.

${ }^{10}$ Downs, T M, Annals of Surgery, 1942, 115, 21.

(Accepted 25 fuly 1979)

\title{
Obstetric anaesthetic and analgesic services in Wales
}

\author{
BRYAN M HIBBARD, GARETH REES, MICHAEL ROSEN
}

British Medical fournal, 1979, 2, 698-700

\section{Summary and conclusions}

A survey of obstetric anaesthetic services in Wales covering 21 major units in which over 31000 deliveries take place annually showed inadequacies in staffing at consultant and resident anaesthetist level. At least 20 additional consultant sessions were required to meet the recommendations of the Association of Anaesthetists of Great Britain and Ireland.

If patients' requests for epidural analgesia are to be met some reorganisation and centralisation of facilities is needed.

\section{Introduction}

Reports on maternal deaths in England and Wales during 1952$72^{1}$ have shown that between 10 and 20 maternal deaths are associated with anaesthesia each year, while the proportion of such deaths had increased to $13.2 \%$ in the latest report (1979). From time to time obstetricians, anaesthetists, midwives, and the public express concern that facilities for obstetric anaesthesia and analgesia are inadequate. We therefore undertook a review of these services in Wales.

Welsh National School of Medicine, Heath Park, Cardiff CF4 4XN BRYAN M HIBBARD, MD, FRCOG, professor of obstetrics and gynaecology South Glamorgan Area Health Authority (Teaching) GARETH REES, MB, FFARCS, consultant anaesthetist MICHAEL ROSEN, MB, FFARCS, consultant anaesthetist

\begin{abstract}
Methods
We obtained data concerning the 20 NHS consultant units and one large general practice unit in which caesarean sections are performed. We derived the distribution of births in Wales by area from data from the Office of Population Censuses and Statistics. ${ }^{2}$ Data on regional analgesia was obtained from the Hospital Activity Analysis. ${ }^{3}$ We used data acquired personally from obstetricians and anaesthetists, based on questionnaires and visits, to provide additional information on the available staff and services and the use of regional analgesia in maternity units.
\end{abstract}

\section{Results}

Over $92.5^{\circ}$, of deliveries in Wales take place in NHS consultant units (table I). This survey therefore covered most births in Wales (over 31000 deliveries). Returns from individual units showed that about 2600 caesarean sections were performed annually.

TABLE I-Number ( $\%$ ) of births by place of confinement for each Area Health Authority in Wales, $1976^{2}$

\begin{tabular}{|c|c|c|c|c|c|c|}
\hline \multirow[b]{2}{*}{$\begin{array}{c}\text { Area } \\
\text { health } \\
\text { authority }\end{array}$} & \multicolumn{6}{|c|}{ Place of confinement } \\
\hline & $\begin{array}{l}\text { NHS } \\
\text { consultant } \\
\text { maternity } \\
\text { units }\end{array}$ & $\begin{array}{l}\text { NHS } \\
\text { general } \\
\text { practitioner } \\
\text { maternity } \\
\text { units }\end{array}$ & Home & $\begin{array}{l}\text { Non- } \\
\text { NHS } \\
\text { hos- } \\
\text { pitals }\end{array}$ & $\begin{array}{c}\text { Else- } \\
\text { where }\end{array}$ & Total \\
\hline Clwyd & $4265(90 \cdot 2)$ & $377(8 \cdot 0)$ & $70(1.5)$ & 1 & 18 & 4731 \\
\hline Dyfed & $3335(92 \cdot 2)$ & $210(5 \cdot 8)$ & $64(1 \cdot 8)$ & & 17 & 3626 \\
\hline Gwent & $4746(90.5)$ & $402(7 \cdot 7)$ & $88(1 \cdot 7)$ & 2 & 6 & 5244 \\
\hline Gwynedd & $2505(95 \cdot 7)$ & $88(3.4)$ & $13(0.5)$ & 1 & 10 & 2617 \\
\hline Mid Glamorgan & $6386(93.5)$ & $247(3 \cdot 6)$ & $185(2 \cdot 7)$ & & 12 & 6830 \\
\hline Powys & $614(50.9)$ & $574(47 \cdot 6)$ & $13(1 \cdot 1)$ & & 5 & 1206 \\
\hline South Glamorgan & $4676(98.9)$ & $12(0 \cdot 25)$ & $39(0.8)$ & 1 & 2 & 4730 \\
\hline West Glamorgan & $4341(98.6)$ & $12(0.27)$ & $49(1 \cdot 1)$ & & 2 & 4404 \\
\hline Wales & $30868(92 \cdot 5)$ & $1922(5 \cdot 8)$ & $521(1 \cdot 6)$ & 5 & 72 & 33388 \\
\hline
\end{tabular}




\section{PROVISION OF ANAESTHETIC}

Consultant staff-Only seven of the 21 units reported having consultant anaesthetic sessions nominated for obstetrics. In these seven units a total of 12 sessions were allocated exclusively to obstetrics, eight of the 12 being in two units in one area. In addition, there were three sessions in which the consultants were responsible for emergency duties elsewhere. In some other units without nominated sessions a consultant anaesthetist undertook the organisation of the local services.

Resident anaesthetic staff (table II)-Only three units, covering $21^{\circ}$ o of all deliveries, had an exclusive 24 -hour service provided by resident anaesthetists. Eight others (45'" of deliveries) had resident staff trained in obstetric anaesthesia, but these staff also undertook other duties. In the remaining 10 units $\left(34^{\circ}{ }^{\circ}\right.$ of deliveries) resident anaes thetists (trained or untrained) were not regularly available within the hospital, either because they were based elsewhere or because there were insufficient anaesthetists to provide a continuous rota.

TABLE II-Resident anaesthetic staff available and proportions of deliveries undertaken at the 21 units

\begin{tabular}{|c|c|c|c|c|c|}
\hline Resident staff & & & & $\begin{array}{l}\text { No of } \\
\text { units }\end{array}$ & $\begin{array}{c}\left.\text { Approximate No ( }{ }^{\circ}{ }^{\circ}\right) \\
\text { of deliveries }\end{array}$ \\
\hline $\begin{array}{l}\text { Exclusive service } \ldots \\
\text { Shared service } \\
\text { Not regularly available }\end{array}$ & $\begin{array}{l}\ldots \\
\cdots \\
\cdots\end{array}$ & $\begin{array}{l}\cdots \\
\cdots \\
\cdots\end{array}$ & $\begin{array}{l}\cdots \\
\cdots \\
\cdots\end{array}$ & $\begin{array}{r}3 \\
8 \\
10\end{array}$ & $\begin{array}{r}7000(21) \\
15000(45) \\
11000(34)\end{array}$ \\
\hline \multicolumn{4}{|c|}{ Total } & 21 & $33000(100)$ \\
\hline
\end{tabular}

Grade of anaesthetists undertaking caesarean section (table III)-We could not obtain precise figures on the grade of anaesthetist undertaking caesarean section because of varying circumstances in individual units, which were dependent on the staff available. Consultants always or usually gave or supervised the anaesthetic in 13 units, in which about half the caesarean sections were performed. At the other end of the scale, in four units the anaesthetic was usually given by a registrar or senior house officer, or general practitioner. Most anaesthetics given as an emergency for caesarean section and other obstetric procedures were administered by junior staff, but precise data could not be obtained.

TABLE III-Grade of anaesthetist most commonly administering anaesthesia for caesarean section

\begin{tabular}{lccc}
\hline & $\begin{array}{c}\text { No of } \\
\text { units }\end{array}$ & $\begin{array}{c}\text { Approximate } \\
\text { deliveries all } \\
\text { Wales }\end{array}$ & $\begin{array}{c}\text { Approximate } \\
\text { Wof all } \\
\text { caesarean } \\
\text { sections in } \\
\text { Wales }\end{array}$ \\
\hline $\begin{array}{l}\text { Consultant personally supervising } \\
\text { Registrar or senior registrar }\end{array}$ & 13 & 56 & 51 \\
Registrar or senior rouse officer & 4 & 28 & 25 \\
General practitioner & 3 & 16 & 23 \\
& 1 & 1 & 0.6
\end{tabular}

Assistance for anaesthetists-An assistant (trained nurse or operatingtheatre technician) was not always available in seven of the 21 units and was never available in two.

Neonatal resuscitation-In eight units (in which a quarter of the caesarean sections were performed) anaesthetists commonly helped with neonatal resuscitation while the mother was still anaesthetised.

Additional resources-Support facilities for managing severely ill or shocked patients were deficient in some units. Electrocardiographs were not available in two units, and there was no defibrillator in three. Five units did not have facilities for measuring central venous pressure. In many units donor blood had to be cross-matched in another hospital always or at certain times.

\section{OBSTETRIC ANALGESIA (table IV)}

Epidural or spinal analgesia was administered to 1020 obstetric patients in Wales in $1976^{\circ}$-that is, about $3^{\circ}$ " of all patients. This correlates reasonably well with the results obtained from the personal questionnaires, in which 1146 epidural anaesthetics were recorded.
TABLE IV-Availability of epidural facilities in consultant units

\begin{tabular}{|c|c|c|c|c|}
\hline $\begin{array}{c}\text { Availability } \\
\text { of } \\
\text { epidural } \\
\text { facilities }\end{array}$ & $\begin{array}{l}\text { No of } \\
\text { units }\end{array}$ & $\begin{array}{l}\text { No }\left({ }^{0}{ }_{0}\right) \text { of } \\
\text { deliveries }\end{array}$ & $\begin{array}{c}\text { No }\left({ }^{\circ} \%\right) \text { of } \\
\text { epidurals given }\end{array}$ & $\begin{array}{l}\text { Epidurals } \\
\text { as o of } \\
\text { deliveries }\end{array}$ \\
\hline $\begin{array}{l}\text { Always } \\
\text { Sometimes } \\
\text { Never }\end{array}$ & $\begin{array}{r}3 \\
11 \\
6\end{array}$ & $\begin{array}{r}6939(22) \\
20636(60) \\
5425(18)\end{array}$ & $\begin{array}{r}1032(90) \\
114(10)\end{array}$ & $\begin{array}{r}15 \\
0 \cdot 6\end{array}$ \\
\hline Total & 20 & $33000(100)$ & $1146(100)$ & $3 \cdot 4$ \\
\hline
\end{tabular}

Epidural analgesia on the mother's request was always available in three units $\left(22^{\circ}\right.$ of all deliveries) and was used by $15^{\circ} \%$ of mothers. Over $90^{\circ}$ of all epidurals administered in Wales were given in these units. In 11 consultant units $(60 \%$ of deliveries) epidural analgesia was administered only occasionally when anaesthetic staff were available. In the remaining six consultant units $(18 \%$ of deliveries) epidural analgesia was never used. In six units in which epidural analgesia was used midwives undertook the "top-up" injections, but the extent of their training and their ability to deal with potential consequential complications was not clear. The medical and midwifery staff of 15 units specifically regretted the lack of resources to provide epidural analgesia regularly.

\section{Discussion}

A survey in 1977 carried out by the Obstetric Anaesthetic Subspecialty Committee of the Association of Anaesthetists of Great Britain and Ireland ${ }^{4}$ showed that the provision of consultant sessions in the UK was generally inadequate. The present detailed study in Wales confirms this. The recommendations of that committee for reasonable standards of anaesthetic service alone were that there should be a minimum of one consultant session per week per 1000 deliveries and a higher proportion in maternity units where fewer than 1000 deliveries occur. This rider has special implications for rural Wales. At present the allocation in Wales is less than one session per 2000 deliveries and outside the teaching hospitals is less than one session per 4000 deliveries. On this basis there is a deficiency of at least 20 consultant obstetric anaesthetic sessions in Wales. Providing specific consultant sessions allocated to obstetric units would probably also lead to improvements in junior and technical staffing and inadequate support facilities. This development should be given a higher priority by health authorities. In 10 obstetric units no resident anaesthetic staff were available on a 24-hour basis. Progress towards this objective could be achieved by both increasing the number of junior anaesthetic staff and the rationalising and amalgamating obstetric services within the district general hospital as recommended. ${ }^{5}$

The need for the anaesthetist to resuscitate the newborn infant while looking after the anaesthetised mother is dangerous. When a trained, skilled paediatrician is not available to participate in caesarean section it is essential that someone else is present to undertake resuscitation of the infant. In some obstetric units few or no assistants were available for the anaesthetist ; these were generally small units in which the work load was inadequate to maintain economically 24 -hour cover of properly trained nursing staff or operating-theatre technicians. A broader based technical grade of staff who are trained to help the anaesthetist and to carry out other duties in the obstetric unit should be considered.

In the units in Wales where epidural analgesia is freely available it was requested for $15^{\circ}{ }_{0}$ of deliveries. If this represents the overall demand, then in a unit with 1000 deliveries yearly an average of only about three epidurals would be administered each week. To provide continuous anaesthetic cover for this number of patients would clearly be economically impossible even if the manpower was available, so that alternative solutions must be sought. Obstetricians might undertake more epidural injections. Many, however, either do not wish to do so or do not have sufficient time or the necessary skills. 
Using midwives to supervise and top-up epidural analgesia undoubtedly encourages more anaesthetists and obstetricians to insert the catheter initially for induction of analgesia, as they do not have to be in virtually continuous attendance during the labour. Supervision and topping up of epidurals, however, cannot safely be left in the hands of medical or nursing personnel unless they have been fully trained and can maintain their skill in dealing with complications and emergencies that may include the need for urgent endotracheal intubation. Therefore, providing a 24-hour rota of midwives trained to undertake this work should be considered. Any training course must include full and practical instruction in possible resuscitation procedures; thereafter, there must be continuing inservice opportunities to practise these skills. It would also help if the resources for epidural analgesia were concentrated in centres that could offer a 24-hour service. Patients asking for epidural analgesia could then be booked at such units, the personal cost of their preference being the need to travel to a centre perhaps not so conveniently situated geographically.

The public demand for epidural analgesia stems from the knowledge of its efficacy. In only a few cases are there potential medical benefits from epidural analgesia. Thus in attempting to provide every mother with the comfort and safety that is her right during childbirth we should also develop more effective methods of pain relief, widely applicable in the present and foreseeable context of obstetric practice.

We should like to thank all the obstetricians and anaesthetists who contributed data on which this study is based.

\section{References}

${ }^{1}$ Report on Confidential Enquiries into Maternal Deaths in England and Wales 1973-1975, Report on Health and Social Subjects, No 14. London, HMSO, 1979.

${ }^{2}$ Office of Population Censuses and Surveys, Vital Statistics, Form SD52 for Wales, 1976.

${ }^{3}$ Hospital Activity Analysis. Cardiff, Welsh Office, 1976.

4 Scott, D B, Report to Association of Anaesthetists of Great Britain and Ireland. London, AAGB and I, 1978.

${ }^{5}$ Report of Anaesthetic Advisory Committee for Wales. Cardiff, Welsh Office, 1973.

(Accepted 26 fuly 1979)

\section{Summary and conclusions}

In a prospective study designed to assess the influence of bromocriptine on pituitary tumour size 12 patients with pituitary tumours, eight of whom had suprasellar extensions, were treated for three months with $20 \mathrm{mg}$ of bromocriptine daily after a gradual increase to this dose. The group comprised eight women and four men, five with prolactin-secreting adenomas, four with acromegaly, two with functionless adenomas, and one with Nelson's syndrome. All five patients with prolactinsecreting adenomas showed a reduction in pituitary tumour size as assessed by computerised tomography and metrizamide cisternography accompanied by a fall in prolactin concentrations and clinical and biochemical improvement in their hypopituitarism. One patient in this group had a visual-field defect before treatment, and this resolved. There was no radiological evidence of reduction in tumour size in the remaining seven patients, though this might reflect the fairly short duration of treatment, particularly in view of the ancillary evidence of clinical, biochemical, and visualfield improvement in some of the patients.

These results emphasise the potential value of bromocriptine in treating patients with large prolactinomas or

Endocrine Unit, Department of Medicine, Royal Victoria Infirmary, Newcastle upon Tyne NE1 4LP

A M MCGREGOR, MB, MRCP, research associate

M F SCANLON, MB, MRCP, first assistant

R HALL, MD, FRCP professor of medicine

Department of Neuroradiology, Newcastle General Hospital, Newcastle upon Tyne

K HALL, MB, FRCR, consultant neuroradiologist recurrences of such tumours after previous chiasmal decompression and conventional external megavoltage irradiation to the pituitary.

\section{Introduction}

The management of patients with pituitary tumours, particularly macroadenomas, remains unsatisfactory. ${ }^{1}$ The development of prolactin radioimmunoassays ${ }^{2}$ has shown that about two-thirds of the so-called "non-secretory chromophobe adenomas" are, in fact, prolactinomas. ${ }^{3}$ This finding, along with the introduction of bromocriptine, an ergot derivative ${ }^{4}$ with long-acting dopamine agonist properties ${ }^{j}$ that inhibits prolactin secretion, has added a new dimension to the treatment of pituitary tumours. While transsphenoidal surgery may result in high cure rates for patients with small prolactinomas (microadenomas), the cure rate falls with increasing tumour size.$^{6-10}$ Conventional irradiation alone rarely lowers prolactin concentrations into the normal range, ${ }^{10} 11$ though results of long-term follow-up of patients treated by this method are awaited.

Several reports are now available on using bromocriptine in patients with hyperprolactinaemia irrespective of cause $\mathrm{e}^{12-14}$ and show a rapid restoration of normal gonadal function, with fall of prolactin concentrations. Many of these patients have been receiving treatment for up to seven years without ill effect. With return of gonadal function an increasing number of women have become pregnant ${ }^{1516}$ with no evidence of teratogenicity in their offspring. While bromocriptine has made a dramatic impact on the treatment of hyperprolactinaemia, its precise role in managing prolactinomas, particularly large tumours, has remained controversial, largely owing to uncertainty about its influence on tumour growth. The tendency has therefore been to treat such patients with surgery or irradiation to the pituitary, supplementing this treatment when necessary with bromocriptine.

The antitumour effect of ergot alkaloids on prolactinsecreting adenomas in the rat is well recognised. ${ }^{1-19} \mathrm{~A}$ similar 